\title{
Análisis de materiales didácticos digitales para guiar y/o apoyar el proceso de enseñanza- aprendizaje de las matemáticas
}

Analysis of Digital Teaching Materials to Guide and/or Support the Teaching-Learning Process of Mathematics

\author{
Dorinda Mato-Vázquez \\ Facultade de CC. da Educación. Universidade da Coruña \\ m.matov@udc.es \\ $\mathrm{M}^{\mathrm{a}}$ Montserrat Castro-Rodríguez \\ Facultade de CC. da Educación. Universidade da Coruña \\ maria.castror@udc.es \\ Ma Camino Pereiro-González \\ CPI Plurilingüe Virxe da Cela (A Coruña) \\ pereirogonzalez@edu.xunta.es
}

Fecha presentación: 06/03/2018 | Aceptación: 17/05/2018 |Publicación: 22/06/2018

\begin{abstract}
Resumen
Las tecnologías digitales han supuesto una revolución en todos los ámbitos de la vida: tecnológico, empresarial, comunicativo, cultural, e incluso en el conocimiento y el entretenimiento. En el panorama educativo tiene también su reflejo y las metodologías y recursos se han redibujado, en cuanto a los diferentes soportes, canales, lenguajes, narrativas, etc. Estos cambios, sustantivos y profundos, afectan simultáneamente al profesorado, alumnado y familias, pero otros agentes como las administraciones educativas y el sector editorial también se ven involucrados. En esta investigación analizamos una muestra de portales institucionales y plataformas comerciales que ofertan recursos didácticos digitales en el área de matemáticas en la Comunidad Autónoma de Galicia. Nos centramos en el tipo de materiales, el modelo pedagógico que subyace a los mismos, las diferencias entre las plataformas comerciales y las institucionales, su utilización, impacto en la enseñanza y el aprendizaje de las matemáticas en el aula, etc. El instrumento utilizado fue un cuestionario diseñado ad hoc y validado y administrado a 13 plataformas comerciales; tanto las producidas comercialmente por empresas editoras como las de naturaleza institucional generadas por las administraciones autonómicas de Canarias, Galicia y Valencia. Los resultados indican que, aunque el abanico de oferta online de materiales didácticos para matemáticas es amplio y con formatos variados, estos tienen carencias pedagógicas que no favorecen metodologías activas ni una verdadera integración de otras alternativas que faciliten el desarrollo de proyectos educativos abiertos, flexibles, que faciliten la atención a la diversidad individual y colectiva de cada persona, así como la participación, la interactividad/conectividad de la comunidad educativa, ya que la mayoría reproducen el formato del libro de texto impreso añadiendo algunos recursos online.
\end{abstract}

Palabras clave: recursos matemáticos; libro de texto digital; materiales didácticos digitales, sociedad digital

\section{Resum}

Les tecnologies digitals han suposat una revolució en tots els àmbits de la vida: tecnològic, empresarial, comunicatiu, cultural, i fins i tot en el coneixement i l'entreteniment. En el panorama educatiu té també el seu reflex i les metodologies i recursos s'han redibuixat, pel que fa als diferents suports, canals, llenguatges, narratives, etc. Aquests canvis, substantius i profunds, afecten simultàniament al professorat, alumnat i famílies, però altres agents com les administracions educatives i el sector editorial també es veu involucrat. En aquesta investigació analitzem una mostra de portals institucionals i plataformes comercials que ofereixen recursos didàctics digitals en l'àrea de matemàtiques a la Comunitat Autònoma de Galícia. Ens centrem en el tipus de materials, el model pedagògic subjacent als mateixos, les diferències entre les plataformes comercials i les institucionals, la seva utilització, impacte en l'ensenyament i 
Mato-Vázquez, Dorinda; Castro-Rodríguez, Mª Montserrat; Pereiro-González, Mª Camino (2018)."Análisis de materiales didácticos digitales para guiar y/o apoyar el proceso de enseñanza-aprendizaje de las matemáticas " @tic revista d'innovació educativa, 20. 72-79.

l'aprenentatge de les matemàtiques a l'aula, etc.L'instrument utilitzat va ser un qüestionari dissenyat ad hoc i validat i administrat a 13 plataformes comercials; tant les produïdes comercialment per empreses editores com les de naturalesa institucional generades per les administracions autonòmiques Canàries, Galícia i València. Els resultats indiquen que, tot i que el ventall d'oferta en línia de materials didàctics per a matemàtiques és ampli $i$ amb formats variats, aquests tenen mancances pedagògiques que no afavoreixen metodologies actives ni una veritable integració d'altres alternatives que facilitin el desenvolupament de projectes educatius oberts, flexibles, que facilitin l'atenció a la diversitat individual i collectiva de cada persona, així com la participació, la interactivitat / connectivitat de la comunitat educativa, ja que la majoria reprodueixen el format del llibre de text imprès afegint alguns recursos en línia.

Paraules clau: recursos matemàtics; Ilibre de text digital; materials didàctics digitals; societat digital

\begin{abstract}
Digital technologies have brought about a revolution in all areas of life: technological, business, communicative, cultural, and even in knowledge and entertainment. In the educational landscape it also has its reflection and the methodologies and resources have been redrawn, in terms of different media, channels, languages, narratives, etc. These changes, substantive and profound, affect all the society simultaneously, but other agents as educational administrations and the publishing sector is also involved. In this research we analyze a sample of institutional portals and commercial platforms that offer digital didactic resources in the area of mathematics in the Autonomous Community of Galicia. We focus on the type of materials, the pedagogical model that underlies them, the differences between commercial and institutional platforms, their use, impact on teaching and learning mathematics in the classroom, etc. The instrument used was a questionnaire designed ad hoc and validated and administered to 13 commercial platforms; both those produced commercially by publishing companies and those of an institutional nature generated by the regional administrations of the Canary Islands, Galicia and Valencia. The results indicate that, although the range of online offer of didactic materials for mathematics is wide and with varied formats, they have pedagogical shortcomings that do not favor active methodologies or a true integration of other alternatives that promote the development of open, flexible educational projects that facilitate the attention to the individual and collective diversity of each person, as well as the participation, interactivity / connectivity of the educational community, since most reproduce the format of the printed textbook by adding some online resources.
\end{abstract}

Key Words: mathematical resources; digital textbook; digital didactic materials; digital society

\section{Introducción y estado de la cuestión}

Promover la innovación, el cambio y la mejora de la calidad en los sectores productivos, sociales y culturales está siendo en los últimos años una constante a nivel mundial. En Educación, y concretamente en matemáticas, los especialistas e investigadores trabajan por la apertura de nuevos escenarios de colaboración, espacios físicos formativos distintos a los tradicionales o recursos didácticos que promuevan el desarrollo curricular en el aula y en la sociedad en general.

En este contexto, en el año 2005, la cumbre Mundial sobre la Sociedad de la Información (CMSI) manifestó que las Tecnologías de la Información y la Comunicación (TIC) son un recurso fundamental para favorecer el acceso a una educación de calidad en el marco de un proceso de responsabilidad social, sentando de esta forma las bases para la creación de una Sociedad de la Información, alejada de exclusiones y orientada al desarrollo y al conocimiento a lo largo de la vida. En nuestro estado, a nivel educativo, la Ley Orgánica $2 / 2006$, de 3 de mayo, de Educación y su posterior modificación por la Ley para la Mejora de la Calidad Educativa asientan las TIC como medio necesario para el aprendizaje y conocimiento de la realidad y como recurso de adaptación a los cambios sociales y económicos actuales. Así, establece su tratamiento transversal en todas las etapas del sistema educativo nacional (MEC, 2011).

De esta forma, y aunque los medios didácticos tradicionales siguen manteniendo su estatus de primacía, los distintos agentes educativos: profesorado, alumnado, familias, administraciones y empresas del sector editorial, coinciden en apostar por cambios sustantivos y profundos en la dotación y uso de recursos educativos digitales en las aulas (Area y Sanabria, 2014: 37) y en espacios no formales de aprendizaje.

Normalmente, se encuadran en repositorios de recursos y en entornos virtuales de aprendizaje (EVA). Unos son públicos, gratuitos y abiertos (OER, Open Educational Resources o REA en español, Recursos Educativos Abiertos) y otros privativos, de pago y cerrados. Si nos centramos en Ios REA, estamos ante un abanico de recursos y materiales educativos digitales, propios del ámbito escolar, pero que a su vez permiten crear conocimiento y aprendizaje en ámbitos no tan formales pero a su vez especializados. Esto es gracias a su configuración como recursos en abierto y a su polivalencia y especialización, lo que permite que sean utilizados en contextos profesionales muy diversos y distantes entre sí.

Por otro lado, teniendo en cuenta que el objeto de esta investigación la centramos en el ámbito matemático, conviene resaltar que los y las profesionales de la Matemática estamos con Marta-Lazo y Gabelas (2016) en que, en la convergencia digital residen los diferentes soportes, canales, lenguajes y narrativas y se abre la comunicación a un territorio poblado de hibridaciones. Los textos abandonan la linealidad y exploran la transmedialidad. Es más, el gran reto, a día de hoy, es crear o encontrar los recursos multimedia funcionales, que motiven al discente y a cualquier persona interesada en la temática, les ayuden a disfrutar de la disciplina comprendiendo su sentido práctico y funcional (Peirats, Sales y San Martín, 2009) y puedan acceder a un conocimiento cierto y adaptado a las necesidades contextuales, personales y sociales. En definitiva, poder emplear el conocimiento para crear aprendizajes y desarrollar competencias que permitan asumir los 
Mato-Vázquez, Dorinda; Castro-Rodríguez, Mª Montserrat; Pereiro-González, Mª Camino (2018)."Análisis de materiales didácticos digitales para guiar y/o apoyar el proceso de enseñanza-aprendizaje de las matemáticas " @tic revista d'innovació educativa, 20. 72-79.

desafíos sociales con autonomía y desde el pensamiento crítico y creativo (Bruillard, 2015: 603) a través de educomunicación (Gozálvez-Pérez y Contreras, 2014). Es decir, con capacidad de análisis, reflexión y de acción en el momento de tener que establecer propuestas de actuación en los diferentes ámbitos de la realidad social. Esto supondrá un refuerzo para los procesos de desarrollo sustentables que tengan como base los recursos endógenos desde una concepción de ciudadanía global. Al mismo tiempo, deben favorecer la creación tecnológica desde la perspectiva de cultura libre y democrática en contextos comunicativos y dejar de lado la visión consumista e inmovilista de las tecnologías integrando la creación de conocimiento como elemento de valor para comprender su funcionamiento, posibilidades y riesgos (Buckingham, 2008). Se trata de ser críticos ante sus posibilidades y ante la vertiente consumista y de la privacidad para alcanzar un uso tecnológico social y reflexivo, que parta del valor del pensamiento y de la iniciativa persoal (Poullet y Dinant, 2007). Hablamos de dejar de lado la concepción de la tecnología como algo mágico que proporciona información, nos entretiene o nos conecta con los demás y concebirla desde una perspectiva social de desarrollo personal y social.

Así, no ponemos en duda que la digitalización de los espacios y recursos formativos es una realidad; que el monopolio del lápiz, papel, láminas, cuadernos, pizarras, libro impreso tradicional, etc., que han estado en las aulas, en nuestras casas, o en nuestros espacios profesionales, son sustituidos poco a poco por recursos, medios y objetos tecnológicos que conjeturan distintos modos de concebir y entender la enseñanza y el aprendizaje en su generalidad (Rodríguez, Bruillard y Horsley, 2015; Gómez Mendoza, Braga García y Rodríguez Rodríguez, 2016), y de las matemáticas, en particular.

Se ha de tener en cuenta que el proyecto educativo y el método de enseñanza bajo el cual se integra el uso de la tecnología así como de las actividades de aprendizaje que realiza las personas con la misma (Sancho, 1994; Cabero, 2001; Salinas, Aguaded y Cabero, 2004; Area, 2005; De Pablos 2009; Barroso y Cabero, 2010), pueden influir en los logros del alumnado. Por ello, es necesario disponer de evaluaciones acerca de la calidad, cómo se utilizan, su impacto en la interacción social, o sobre cómo el aprendizaje de cada individuo y los resultados difieren según el tipo de recurso utilizado.

Por otra parte, es interesante que las editoriales de cualquier ámbito profesional entiendan el papel que los especialistas de la pedagogía deben jugar a la hora de valorar conceptual y metodológicamente un libro de texto (Slater, 2010: 310) tradicional o digital u otros materiales que tengan una finalidad formativa. De esta forma, el análisis de las plataformas comerciales puede proporcionar una información muy interesante para profesionales, familias y sociedad en general, siendo punto de partida para mejorar en cuanto a los productos que presentan con intención educativa.

Porque, para renovar tecnológicamente y plantear una utilización pedagógica y transformadora de la educación matemática se ha de disponer de un proyecto pedagógico oportuno, adaptar la enseñanza, nuevos planes de estudio, formación del profesorado, etc. (Cabero Almenara y Marín Díaz, 2014). Todo ello antes de aplicar la tecnología (Fullan, 2011; Fullan y Langworthy, 2013). Es decir, que exista colaboración entre las editoriales y los profesionales. Como señala Fernández (2015: 187) la mera sustitución de un tipo de recurso por otro, no transforma las formas de enseñar ni los procesos de aprender. De ahí que la figura del docente de matemáticas (su formación, sus creencias sobre la enseñanza y el aprendizaje, su experiencia previa) es clave y sustantiva en el uso que realizan de las TIC los y las estudiantes en las situaciones de aprendizaje (Gonçalves, Vieira y Nogueira, 2015).

En base a todo lo explicitado anteriormente, en este artículo se presentan los resultados de analizar los materiales o recursos digitales educativos destinados al aprendizaje matemático dentro de las plataformas de contenidos digitales pertenecientes a la Comunidad Autónoma de Galicia (tanto editoriales de ámbito estatal como autonómico).

\section{Método}

\subsection{Muestra}

La selección de la muestra es la siguiente: en primer lugar, se identifican los recursos online que se pueden encontrar en los portales web elaborados en editoriales e instituciones/administración/colectivos / entidades sociales profesionales de Canarias, Galicia, Valencia y otras de carácter estatal que aceptaron colaborar en el proyecto, pero que además cumplían los requisitos de producción y edición de materiales propuestos en el proyecto. En segundo lugar, se seleccionan aquellas que están disponibles en Galicia tanto pertenecientes a la administración, como a otras entidades sociales y las comerciales. De esta selección resultan, Abalar, perteneciente a la Consellería de Cultura, Educación y Ordenación Universitaria, de entidades sociales/instituciones/administración y cinco plataformas de contenidos educativos comerciales de ámbito estatal (Santillana, Edebé, Xtend, Digital Text, Anaya) y tres de la Comunidad gallega (Galinova, Edicións Xerais y Rodeira). En tercer lugar, se analizan en estos repositorios y plataformas de contenidos educativos digitales cuáles tienen material de matemáticas. De esta criba, la muestra quedó reducida a: Santillana, Anaya, Edebé-Rodeira, Aiovai Educación y museos científicos coruñeses. Finalmente con esta muestra se examinan las dimensiones contempladas en el instrumento de análisis: características identificadoras del material o recursos educativos, estructura del material, dimensión tecnológica, dimensión de diseño, dimensión pedagógica, dimensión de contenido, evaluación y seguimiento, características pedagógicas y tecnológicas.

\begin{tabular}{|l|l|l|l|l|l|}
\hline & Material I & Material II & Material III & Material IV & Material V \\
\hline $\begin{array}{l}\text { Tipo de } \\
\text { material }\end{array}$ & $\begin{array}{l}\text { Material de } \\
\text { consulta }\end{array}$ & $\begin{array}{l}\text { Libro de texto } \\
\text { digital (LTD) }\end{array}$ & LTD y MDD & $\begin{array}{l}\text { Material } \\
\text { Didáctico } \\
\text { Digital (MDD) }\end{array}$ & MDD \\
\hline $\begin{array}{l}\text { Edición y y } \\
\text { producción }\end{array}$ & Editorial I & Editorial II & Editorial III & $\begin{array}{l}\text { Museos } \\
\text { cientificos }\end{array}$ & $\begin{array}{l}\text { Colectivo } \\
\text { profesional }\end{array}$ \\
\hline $\begin{array}{l}\text { Ámbito } \\
\text { científico }\end{array}$ & Interdisciplinar & $\begin{array}{l}\text { Ámbito cientifico } \\
\text { definido }\end{array}$ & Interdisciplinar & Interdisciplinar & Interdisciplinar \\
\hline Acceso & $\begin{array}{l}\text { Acceso } \\
\text { restringido }\end{array}$ & $\begin{array}{l}\text { Acceso } \\
\text { restringido }\end{array}$ & $\begin{array}{l}\text { Acceso } \\
\text { restringido }\end{array}$ & Acceso abierto & Acceso abierto \\
\hline
\end{tabular}

Tabla 1. Ficha de características de los materiales analizados 
Mato-Vázquez, Dorinda; Castro-Rodríguez, Mª Montserrat; Pereiro-González, Mª Camino (2018)."Análisis de materiales didácticos digitales para guiar y/o apoyar el proceso de enseñanza-aprendizaje de las matemáticas " @tic revista d'innovació educativa, 20. 72-79.

\subsection{Diseño de la investigación y metodología 2.2.1 Instrumento}

El instrumento utilizado fue un cuestionario elaborado y validado por los equipos que participan en este Proyecto denominado Escuel@ Digita@l,y destacando un total de cinco cuestiones fundamentales (características tecnológicas de los Materiales Didácticos Digitales (MDD) y Libros de Texto Digitales (LTD), modelos didácticos que subyacen en los materiales, modelos sociocomunicativos que favorecen entre los docentes y los estudiantes y diferencias que existen en función de la lengua (gallego, valenciano, español) (Area, 2016: 2). Se utiliza el análisis de contenido como la metodología cualitativa apropiada para analizar las características de los materiales digitales partiendo de la idea transmitida por Bardin (2004: 29) de que "el análisis de contenido es un conjunto de técnicas de análisis comunicativas usando procedimientos sistemáticos y objetivos para describir los contenidos de los mensajes".

Este análisis pretende ser simultáneamente descriptivo e inferencial. Descriptivo en cuanto a que nos proponemos describir exhaustivamente el contenido, tanto a través de su forma, como a través de los temas abordados y su conexión con el currículo oficial. No pudiendo descontextualizar el análisis de contenido y teniendo en cuenta que ese contexto envuelve y rodea los datos sobre determinadas condiciones.

Las cuestiones generales a responder podemos sintetizarlas en:

- ¿Qué tipos de portales y materiales en línea hay para trabajar las matemáticas en el contexto gallego?

- ¿Qué diferencias existen entre los portales de las administraciones (tanto del Ministerio como autonómicas) y las plataformas o portales de las editoriales 0 empresas privadas 0 instituciones sociales?

- ¿Cuáles son las características más destacables de los materiales que se ofrecen en dichos portales con relación a sus dimensiones tecnológicas, pedagógicas y sociocomunicacionales?

- ¿Cuál o cuáles son los modelos didácticos que subyacen en los materiales ofertados?

- ¿Cuál o cuáles son los modelos sociocomunicativos que favorecen los MDD?

Antes de llevar a cabo el análisis del material debemos situar mínimamente lo que entendemos por dichas dimensiones.

En cuanto a la dimensión pedagógica entendemos que la práctica docente diaria debe fomentar que el alumnado aprenda a pensar, sea creativo, crítico y reflexivo; lo que implica que en las clases se incluya el diálogo y la reflexión como referente principal. Además, ha de promover que relacionen los aprendizajes de un área/ámbito/materia y los transfiera a otras situaciones de su vida cotidiana. Que aprenda a convivir ante opiniones diferentes, por lo que el docente debe proporcionar herramientas para que el estudiante sea autónomo y dialogante.

Con respecto a la dimensión de contenido creemos que debería ofrecer la posibilidad de seleccionar el contenido en función de los intereses del alumnado, y que faciliten el conocimiento de la diversidad sociocultural y política existente. También se pretende que favorezca un tratamiento diferenciado en función del contexto social, cultural y ambiental de aplicación, así como de las edades y características de los y las destinatarios/as. Asimismo, que el contenido icónico y textual refleje la diversidad funcional, de género, sexual, cultural, etaria, etc., que responda a las demandas curriculares del curso en cuestión, que exprese la lógica que organiza y que secuencia el contenido y que incluya ámbitos del saber o conocimiento de distinta naturaleza.

\section{Resultados}

A continuación, presentamos los hallazgos y descripción de cada una de las dimensiones analizadas (tecnológicas, pedagógicas y sociocomunicacionales) y en la última parte del texto, incluimos algunas de las principales conclusiones del estudio realizado. También nos detenemos en el análisis de redes educativas y/o asociaciones profesionales que publican materiales.

\subsection{Análisis de las dimensiones \\ 3.1.1 Tipos de materiales}

Desde el punto de vista de la modalidad de materiales de matemáticas que se encuentran en las plataformas gallegas, tanto comerciales como de la variedad de instituciones, los más frecuentes son los LTD en las primeras y los materiales didácticos digitales MDD en las segundas. Estos resultados están en consonancia con los resultados generales de los materiales analizados en las plataformas de las tres comunidades autónomas y las estatales, pero que también son comunes a los materiales elaborados para las distintas áreas de conocimiento.

\subsubsection{Diseño}

El diseño de los materiales presentados es muy desigual. Resulta interesante destacar que la presencia de la imagen es mayoritaria en sus distintas formas y variedades, desde la fotografía hasta diferentes técnicas de dibujo, vídeos, dibujos, esquemas, etc con una función aclaratoria y explicativa, lo que facilita la accesibilidad del conocimiento. En algunos casos, la imagen se complementa con sonidos, lo que aumenta el espectro de la comprensión para el estudiantado.

En cuanto al aspecto estético podemos decir que, en la mayoría, está cuidado; aparecen iconos, imágenes orientativas, estrategias para destacar unos contenidos de otros, etc., que facilitan la accesibilidad y un manejo intuitivo. En el caso de los materiales editados en las plataformas comerciales, si existe una preocupación por la estética del producto (Materiales I, II y III). Las imágenes, la simbología y semiótica, la incorporación de vídeos, sonidos, etc., son de calidad y proporcionan una sensación de estética agradable. Sin embargo, los materiales publicados en otras plataformas no presentan un aspecto tan cuidado (Material IV). Es necesario recordar que los LTD están editados por plataformas comerciales que suelen contar con departamentos y profesionales destinados específicamente al diseño, mientras que en las instituciones a las que pertenecen las plataformas no comerciales no siempre cuentan con equipos profesionales expertos en estas temáticas, a veces son materiales elaborados por profesionales que voluntariamente los producen o bien el aspecto estético no está en las prioridades de los productores de materiales. 
Mato-Vázquez, Dorinda; Castro-Rodríguez, Mª Montserrat; Pereiro-González, Mª Camino (2018)."Análisis de materiales didácticos digitales para guiar y/o apoyar el proceso de enseñanza-aprendizaje de las matemáticas " @tic revista d'innovació educativa, 20. 72-79.

Los LTD analizados suelen corresponderse con los libros en formato impreso en formato pdf, que en el mejor de los casos incluye a mayores links para acceder a alguna web o blog, un vídeo, la ampliación de una imagen, etc, pero realmente no hay un verdadero aprovechamiento de su carácter virtual para favorecer la conectividad.

\subsubsection{Accesibilidad y conectividad}

En cuanto a la accesibilidad a los materiales, se analizó desde distintas perspectiva. Por una parte, los LTD no son de accesibilidad gratuita. El hecho de que sean productos de las editoriales está sujeto a condiciones de uso. Normalmente, pueden acceder a ellos el alumnado, colegios y familias que hayan comprado los libros impresos, a los que se les proporciona un código y/o contraseña. En algunos casos, las editoriales también producen MDD que suelen ser de acceso restringido en las mismas condiciones de los LTD. Los materiales ubicados en las plataformas no comerciales son todos ellos de acceso libre totalmente.

Por otra parte, la accesibilidad también hace referencia a las posibilidades que ofrece cada material para acceder a su uso y manejo. En el caso de los LTD, el hecho de que estén en formato pdf no siempre facilita su manejo, especialmente, en el caso de personas que no tengan las destrezas motrices, coordinación visomotriz, etc. necesarias para realizar algunas actividades, para visualizar o cambiar de página, entre otras acciones, puede ser un obstáculo importante. Sin embargo, la existencia de cierta iconografía y símbolos, algunas herramientas incorporadas para aumentar/reducir, insertar textos y figuras, la posibilidad de ver tridimensionalmente ciertas imágenes resultan muy interesante para trabajar distintos contenidos del área de matemáticas y para una gran diversidad de receptores (Materiales III).

A veces la organización y estructura de la plataforma favorece una navegabilidad sencilla, pero que se dificulta al tener que ir de los visualizadores a los menús principales para avanzar de un tema a otro o, para acceder al material complementario. Esto hace que no sea todo lo intuitiva que debiera, como ocurre en el Material II. Esta cuestión se resuelve positivamente en el Material III o el V, que poseen un diseño muy sencillo pero claro y atractivo, con estructura diáfana y correcta organización, lo que favorece una experiencia de navegación ágil y muy funcional.

Centrándonos en el ámbito de la conectividad, esta se restringe a cuestiones muy básicas como suelen ser acceso a alguna noticia de los medios de comunicación, algún blog o la incorporación de vídeos o colecciones fotográficas que vienen a ampliar la información. La oferta y los enlaces a otros materiales complementarios de carácter digital son muy limitados, no se aprovechan las potencialidades de la red para establecer procesos de indagación, búsqueda y selección de información. Realmente, en ninguno de los materiales analizados se encontraron propuestas de trabajo basadas en la construcción del conocimiento en red, por ejemplo. Incluso en el caso del Material III, que combina LTD y MDD, realmente no se llega a la configuración de un espacio abierto de trabajo, sino que los MDD están vinculados a aspectos muy concretos del LTD. El material $V$ apuesta decididamente por el software libre y ofrece una gran cantidad de recursos de apoyo externos y enlaces de retroalimentación. La mayoría de los materiales se pueden utilizar en diferentes dispositivos como PC, Ipad, Android, Windows App y Responsive, con velocidades de cargas en general buenas y rápidas.

Por lo tanto, la oportunidad de apertura del conocimiento a toda la sociedad y las posibilidades que abre de conectividad para adaptar y contextualizar los procesos de aprendizaje de cada ámbito científico a las necesidades y potencialidades de cada ser humano quedan relegadas a un segundo plano.

\subsubsection{Dimensión pedagógica}

En el análisis de los materiales digitales encontramos diferencias y similitudes significativas entre unos y otros. Los recursos tecnológicos ya de por sí resultan atractivos para el alumnado, lo que en principio, les facilita una mayor implicación. Sobre todo, cuando les permiten aprender a través de juegos y, especialmente, en el caso de aquellos que ofrecen propuestas interactivas. No obstante, en los materiales analizados no es común este tipo de planteamiento. La mayoría de ellos no son concebidos inicialmente desde un punto digital porque es una traslación del libro impreso a formato digital, con algunas adaptaciones, enlaces, etc y la mayor parte de las actividades de los materiales plantean realizarse en la libreta y en el ordenador (Material I).

\section{a) Modelos pedagógicos}

En general, los materiales analizados muestran un modelo pedagógico tradicional, basado en la adquisición de contenidos de carácter conceptual, quedando los demás relegados, tal como la propia ley encubre. Los planteamientos son demasiado lineales y en general no se presenta optatividad en el recorrido didáctico planteado, ni secuenciación de los contenidos y de las actividades, lo que repercute negativamente en la atención a la diversidad, al no responder a los distintos ritmos de aprendizaje.

Con frecuencia, las estrategias para la resolución de las actividades están limitadas a completar, a recortar, a subrayar, repetir estructuras, etc, presentándose como propuestas cerradas, no solo por su manejabilidad o posibilidad reducida de acceder a algunos enlaces limitados (Material II), sino que sus propuestas siguen recogiendo algunos de los importantes problemas que tienen los libros impresos (Material I, Material II). En algunos casos son pesadas, repetitivas, memorísticas, poco interesantes y excesivas, saturan la atención e interés del alumnado; es decir, presentan muchas actividades juntas, individualistas, muy clásicas y poco interactivas, lo que acabará desmotivando o aburriendo al llegar a la mitad de unidad. Sin embargo, en materiales como Material $V$ se favorece el desarrollo de actividades de carácter creativo, reflexivo, crítico, de manejo de distintas fuentes documentales, de la presentación de los procesos de aprendizaje en diversos formativos, con todo, generalmente, no facilitan que estos trabajos puedan subirse a la red y compartirse entre el estudiantado.

Además, el diseño estructural de las actividades y contenidos está muy poco equilibrado, pues en algunas partes es brillante y motivador y en otros lineal y poco interesante.

Contrariamente materiales como Material V presentan actividades bien construidas, enlazadas y coherentes con los principios de trabajo basados en las inteligencias múltiples. Encontramos algunos pedagógicamente consistentes y potenciadores de un aprendizaje relevante, crítico y reflexivo. Algunos fomentan la 
Mato-Vázquez, Dorinda; Castro-Rodríguez, Mª Montserrat; Pereiro-González, Mª Camino (2018)."Análisis de materiales didácticos digitales para guiar y/o apoyar el proceso de enseñanza-aprendizaje de las matemáticas " @tic revista d'innovació educativa, 20. 72-79.

investigación autónoma del alumnado, y aunque mayoritariamente potencian el trabajo individual, algunos facilitan el trabajo colaborativo fuera del uso del aparato tecnológico; se puede trabajar con los materiales tanto on-line como off-line. Otros posibilitan enlaces a otros recursos de la propia red e incluso algunos facilitan que el profesorado pueda organizar propuestas personalizadas. Suelen ser de acceso rápido y no llevan a confusión o pérdida de tiempo, ya que los cambios de tarea son inmediatos. Algunos recursos pueden ser editados por el propio profesorado, permitiendo así adaptarlos a sus estudiantes. En el caso de un material, incluso se busca la participación activa del alumnado para realizar las actividades fuera del entorno virtual, por ejemplo este libro parte de las experiencias, de las reflexiones, de las vivencias del estudiante que se irá enriqueciendo con la búsqueda de información en otras fuentes documentales, a veces dentro de la propia red, y en otras ocasiones fuera.

Y también se encuentran casos duales, algunos LTD se presentan propuestas didácticas basadas en el trabajo por proyectos. En este caso, presentan la unidad, de los contenidos, pero luego se han de desarrollar fuera del propio libro.

Sólo materiales como el Material V permiten responder a los intereses del alumnado, porque les dan un rol activo en cuanto que son ellos los que tienen que decidir qué opciones eligen para ir desarrollando la actividad.

Otro inconveniente es que la oferta de materiales de apoyo, como vídeos o enlaces, es poco atractiva visualmente, lineales, monótonos y aburridos (Material IV). Tampoco tienen en cuenta los diferentes ritmos de aprendizaje que pueda presentar la diversidad de alumnado. No existe, por lo tanto, una oferta de actividades de apoyo o refuerzo educativo, que facilite el aprendizaje de las personas destinatarias que presenten necesidades educativas.

En general, las actividades están pensadas para resolverse de modo individual y no disponen de canales - medios para trabajar de forma cooperativa o establecer relaciones entre agentes educativos y se percibe una excesiva subordinación del profesorado a los materiales presentados.

\section{b) Organización y estructura}

En general, un material de buena calidad presta atención a la organización y estructura, porque facilitan su comprensión en tanto que utilizan distintas estrategias para destacar la información relevante de la complementaria y permite que el profesorado edite de forma simple el material en formato digital y guarde distintas versiones del mismo para hacérselo llegar al alumnado con distinta estructura y contenido (Material I).

\section{c) Núcleos temáticos}

En general se repiten los núcleos temáticos en el caso de los LTD, quizás los MDD en este sentido permitan la introducción de temas diferentes, especialmente en el caso de aquellos elaborados y editados por colectivos e instituciones sociales que trabajan específicamente en ámbitos especializados (Material IV). En el caso de los LTD se opta por temáticas que se consideran de interés general de los colectivos destinatarios y no se aprecian realidades próximas al alumnado e incluso ofreciendo una visión unívoca e irreal de Galicia. Es cierto que también algunos materiales abordan temáticas que giran alrededor del entorno sociocultural gallego y en la funcionalidad del idioma gallego (Material III, IV y V). Tan solo el material $\mathrm{V}$ presenta contenidos de carácter intergeneracional, tratando de estimular el contacto y comprensión de la realidad sociocultural próxima. Hay contenidos que no aparecen a lo largo de los materiales analizados, salvo excepciones. Entre ellos no se integra la diversidad lingüística y sociocultural de Galicia sólo se visibiliza en uno de los recursos (Material I, Material II). Las personas con diversidad sexual, funcional, cultural o etaria de la población y de la sociedad, son ignoradas, en la mayoría de los materiales (Material I). Algunos lo tocan muy débilmente, lo que repercute en la reproducción de estereotipos que vinculan lo habitual con lo normal y relacionan la diversidad con lo extraño o lo desconocido. Las referencias a personas con diversidad funcional, cultural o ancianos son escasos o nulas y aparecen concepciones clasistas en torno a la mujer, a la pareja heterosexual, modelo familiar, etc.

\section{d) Organización y secuenciación de la propuesta didáctica}

Una característica destacable es la conexión de los contenidos. En principio, cuatro de los cinco materiales, excepto el Material II, están elaborados con vocación de interdisciplinariedad, tanto en los LTD como en los MDD. Con frecuencia aparecen asociados simultáneamente a distintos ámbitos científicos como las matemáticas al ámbito lingüístico y al ámbito de las ciencias sociales y/o naturales. $\mathrm{Y}$ aunque los cuatro, en sus principios teóricos, argumentan su carácter interdisciplinar, especialmente los LTD y están estructurados secuencialmente de menor a mayor complejidad (Material I); sin embargo, no siempre hacen propuestas de actividades, tareas y temas a trabajar respondiendo a la conexión de contenidos, sino que las propuestas didácticas de cada materia se presentan en un mismo "tema" o "lección", aunque cada materia suele estar en una página diferente, sin apenas vinculaciones de contenidos.

Sin embargo, en la muestra analizada, tan solo uno de los materiales, el Material $\mathrm{V}$ presenta una secuencia didáctica interdisciplinar muy completa y bien diseñada, pedagógicamente consistente y potenciadora de un aprendizaje relevante, crítico y reflexivo. A través de actividades muy bien construidas, enlazadas y coherentes con los principios de trabajo de las inteligencias múltiples, fomenta la investigación autónoma del alumnado, así como el trabajo cooperativo y el aprendizaje colaborativo, que constituyen uno de los principales pilares de la propuesta educativa. La secuenciación del contenido es acertada. En el Material IV se presentan tres proyectos.

En cuanto a la estructura de cada unidad, en general, señalan claramente los contenidos más relevantes y sintéticos (Material I), lo que puede ayudar al estudiante a ubicarse mejor para consultar dudas o cuestiones puntuales.

\section{e) Lenguajes}

En cuanto a los lenguajes y formatos empleados son sencillos, muy semejantes al formato, estructura y presentación que nos ofrecen los libros impresos, muy tradicionales. El lenguaje, enunciados e imágenes ofrecidas no siempre están acordes a la edad y características psicológicas de sus destinatarios/as. A estas edades ya empiezan a cuestionar el sentido y la necesidad de abordar estos aprendizajes; muestran 
Mato-Vázquez, Dorinda; Castro-Rodríguez, Ma Montserrat; Pereiro-González, Mª Camino (2018)."Análisis de materiales didácticos digitales para guiar y/o apoyar el proceso de enseñanza-aprendizaje de las matemáticas " @tic revista d'innovació educativa, 20. 72-79.

actitudes de frustración o un desinterés generalizado por aprender matemáticas porque no las comprenden, se aburren o se cansan con la monotonía de las clases (Material IV).

Al mismo tiempo, cuenta con apéndices de consulta al finalizar los contenidos que pueden ser relevantes para el alumnado a la hora de realizar ejercicios, resolver dudas o completar información (Material I). Por lo que, como material de consulta puntual, puede ser interesante, especialmente para ayudar al alumnado a resumir o destacar la información relevante que en el libro de texto pueda ser más extensa.

\section{Discusión y conclusiones}

Como hemos visto a lo largo de estas líneas, los cambios, sustantivos y profundos en las formas $y$ maneras de aprender, afectan no solamente a la creación y producción de materiales y recursos educativos, sino también a la forma y uso que de los mismos realizan profesorado, alumnado, familias y sociedad en general. En un primer momento puede parecer que la incorporación de las tecnologías en el ámbito formativo, tanto formal como informal, es un gran avance y genera una mejora sustancial en la calidad de la enseñanza y el aprendizaje. En el ámbito de la enseñanza de las matemáticas cobra especial importancia la utilización de recursos que faciliten la atención a las necesidades específicas de cada estudiante $\mathrm{y} / \mathrm{o}$ usuario, tanto en cuanto a motivación como a proporcionar actividades y tareas que faciliten la accesibilidad al conocimiento y a su utilidad práctica. Pero esto, ciertamente no siempre es así. Como hemos visto, son numerosas las investigaciones que destacan la necesidad de contar con un modelo claro de introducción de las tecnologías en el ámbito formativo, asentado en sus finalidades y no en la tecnología en sí misma. Agentes como administraciones educativas o el sector editorial determinan en demasía el modelo implantado. Así, destacaremos investigaciones en los distintos continentes, que se centran fundamentalmente en los LTD (Rodríguez, Bruillard y Horsley, 2015; Rodríguez Rodríguez y Rodríguez Regueira, 2016) y siendo escasos las que se centran en los MDD (Mesa, Nuñez y Chacón, 2017). A la luz de estos trabajos, se constata que los LTD analizados en esta muestra presentada en este artículo, son representativos de las tipologías dominantes en las plataformas digitales, tanto promovidas por instituciones públicas como privadas en muchas partes del mundo. Por eso, son necesarios procesos evaluativos rigurosos que abarquen las diferentes dimensiones que configuran recursos y materiales formativos que tienen su base en recursos tecnológicos. En esta base, se asienta la investigación de I+D+i presentada denominada Escuel@ Digit@।.

Así, vimos que los recursos y medios analizados presentan diferencias significativas entre los MDD y LTD que se albergan en las plataformas de instituciones públicas y privadas. Los LTD son elaborados fundamentalmente por editoriales, que suelen trasladar a formato digital lo que está en formato impreso. En general, la apuesta que hacen por el diseño, su maquetación, la introducción de imágenes, fotos, vídeos, enlaces a webs, blogs, introducen aspectos interesantes desde el punto de vista estético. Sin embargo, no se percibe un buen aprovechamiento de las posibilidades de la interactividad y la adaptación a las características individuales de cada usuario. En general, son materiales que presentan modelos pedagógicos tradicionales y escasamente apuestan por la introducción de propuestas didácticas basadas en metodologías innovadoras. Es decir, los LTD no suelen ser más que un traspaso de los LTI a formato digital (Rodríguez Rodríguez y Martínez Bonafé, 2016). Las instituciones sociales públicas y privadas suelen presentar MDD, que son muy diferentes en cuanto a formatos y contenidos. En general, suelen trabajar temáticas distintas a las habituales, abordadas con profundidad. Es muy dispar el modelo pedagógico entre unas propuestas y otras e incluso en muchas ocasiones no se percibe con claridad cuáles sus fundamentos. El diseño suele ser más simple que en el caso de los LTD.

\section{Bibliografía}

Area, M. (2005). La educación en el laberinto tecnológico. De la escritura a las máquinas digitales. Barcelona: Octaedro.

Area, M. (2015). Resumen Memoria Técnica del Proyecto Escuel@ Digital (EDU2015-64593-R). La escuela de la sociedad digital: análisis y propuestas para la producción y uso de los contenidos digitales educativos, financiado por el Plan Estatal de $1+D+i$. I.P. Manuel Area (Documento oficial, difusión restringida).

Area, M. y Sanabria, A.L. (2014). Opiniones, expectativas y valoraciones del profesorado participante en el Programa Escuela 2.0 en España. Educar, 50(1), 1539. https://doi.org/10.5565/rev/educar.64

Barrera, M. D. R., Chávez F. J., Hernández, H. A. (2008). Representaciones sociales de los sujetos en la sociedad del conocimiento. Ponencia del IX Encuentro Virtual Educa Zaragoza.

Barroso, J., y Cabero, J. (2010). La investigación educativa en TIC. Madrid: Síntesis.

Buckingham, D. (2008). Repensar el aprendizaje en la era de la cultura digital. Revista El monitor de la Educación, 18, 1-4.

Bruillard, E. (2015). Digital textbooks: current trends in secondary education in France. En: Rodríguez Rodríguez, J., Bruillard, E. y Horsley, M. (coords). Digital Textbooks, What's New? Santiago de Compostela: IARTEM/Servizo de Publicacións USC.

Cabero, J. (2001). Tecnología educativa: diseño y utilización de medios en la enseñanza. Barcelona: Paidós.

Cabero Almenara, J., Marín Díaz, V. (2014). Miradas sobre la formación del profesorado en tecnologías de información y comunicación (TIC). En/@ce. Revista Venezolana de Información, 11(2), 11-24. Recuperado de: http://ir.uv.es/vHU4MuG

De Pablos Pons, J. (2009). Tecnología educativa. Málaga: Ediciones Aljibe.

Fernández, A. (2015). Exploration on new roles and changes in E-books in Education. En: Rodríguez Rodríguez, J.; Bruillard, E.; Horsley, M. (coords). Digital Textbooks, What's New? Santiago de Compostela: IARTEM/Servizo de Publicacións USC. 
Mato-Vázquez, Dorinda; Castro-Rodríguez, Mª Montserrat; Pereiro-González, Mª Camino (2018)."Análisis de materiales didácticos digitales para guiar y/o apoyar el proceso de enseñanza-aprendizaje de las matemáticas " @tic revista d'innovació educativa, 20. 72-79.

Fullan, M. (2011). Whole system reform for innovative teaching and learning. In Microsoft-ITL Research (Ed.), Innovative Teaching and Learning Research, 30-39. Recuperado de: http://ir.uv.es/V05I9la

Fullan, M. y Langworthy, M. (2013). Towards a new end: New pedagogies for deep learning. Seattle, Washington: Collaborative Impact.

Gozálvez-Pérez, V., y Contreras-Pulido, P. (2014). Empowering media citizenship through educommunication. Comunicar, 42, 129-136. https://doi.org/10.3916/C42-2014-12

Gómez, M. A., Braga, T. y Rodríguez, J. (2016). Balance y análisis sobre la investigación del texto escolar y los medios digitales. Memorias de la Conferencia Regional para América Latina de la IARTEM. Colombia: Universidad Tecnológica de Pereira.

Gonçalves, D.; Vieira Silva, C. y Claudia Noguera, I. (2015). Future teachers' perceptions of the pedagogical use of digital textbook in the learning process. En: Rodríguez Rodríguez, J.; E. Bruillard y Horsle. M. (Eds.) (2015)). Digital Textbooks, What's New?. Santiago de Compostela: IARTEM/Servizo de Publicacións USC.

López Carreño, R. (2007). Los portales educativos: clasificación y componentes, en Anales de Documentación, 10, 233-244. Recuperado de http://revistas.um.es/analesdoc/article/view/1171

Marta-Lazo, C. y Gabelas, J. A. (2016). Comunicación Digital. Un modelo basado en el factor Relacional. Barcelona: UOC.

MEC (2006). Ley Orgánica (LOE) 2/2006, de 3 de mayo, de Educación. BOE n 106 de 4 de mayo de 2006 (Texto consolidado: última actualización 29/07/2015)

Mesa, A. L. S., Nuñez, Q. Á. y Chacón, J. P. (2017). Las políticas educativas en la producción y distribución de materiales didácticos digitales. RELATEC: Revista Latinoamericana de Tecnología Educativa, 16(2), 6377. https://doi.org/10.17398/1695-288X.16.2.63

Ortega, M.L. (2010). Comunicación y educación para el desarrollo en la estrategia de educación para el desarrollo española. En: Teresa Burgui y Javier Erro (coords.), Comunicando para la solidaridad y la cooperación, cómo salir de la encrucijada. Pamplona: Foro Comunicación, Educación y Ciudadanía.

Peirats Chacón, J., Gallardo Fernández, I. M., San Martín Alonso, Á., y Waliño Guerrero, M. J. (2016). Análisis de la industria editorial y protocolo para la selección del libro de texto en formato digital. Profesorado,
Revista de Currículum y Formación del Profesorado, 20(1), 74-89. Recuperado de: http://www.ugr.es/local/recfpro/rev201ART5.pdf

Peirats, J., Sales, C., y San Martín, A. (2009). Un" portátil por estudiante" como argumento de disputa política en la sociedad digital. Educatio siglo XXI, 27(2), 53$70 . \quad$ Recuperado de: http://revistas.um.es/educatio/article/view/90961

Poullet, Y., Dinant, J. M. (2007). Hacia nuevos principios de protección de datos en un nuevo entorno TIC. IDP: revista de Internet, Derecho y Política $=$ Revista d'Internet, Dret i Política, (5), 33-46. Recuperado de: http://ir.uv.es/T9nQ8Z0

Reig, D. (2012). Disonancia cognitiva y apropiación de las TIC. Telos, 90, 9-12. Recuperado de: http://ir.uv.es/rOlgqPh

Rial, A., Gómez, P., Braña, T., y Varela, J. (2014). Actitudes, percepciones y uso de Internet y las redes sociales entre los adolescentes de la Comunidad Gallega (España). Anales de Psicología, 30(2), 642655. Recuperado de: http://ir.uv.es/aTJ02rV

Rodríguez, Gl. (2005). Cumbre mundial sobre la sociedad de la información: Desafíos. Frónesis, 12(2).

Rodríguez Rodríguez, J. y Martínez Bonafé, J. (2016). Libros de texto y control del curriculum en el contexto de la sociedad digital. Cadernos Cedes, 36 (100), 319-336. 32622016171317

Rodríguez Rodríguez, J.; E. Bruillard y Horsley. M. (Eds.) (2015). Digital Textbooks, What's New? Santiago de Compostela: Servizo de Publicacions da USC/IARTEM.

Rodríguez Rodríguez, J., y Rodríguez Regueira, N. (2016). Revisión de la investigación publicada sobre el libro de texto digital en revistas, publicaciones y congresos internacionales de referencia. Profesorado. Revista de Currículum y Formación de Profesorado, 20(1), 931. Recuperado de: http://ir.uv.es/c0Wdk6W

Salinas, J.; Aguaded, J. I. y Cabero, J. (2004). Tecnologías para la Educación. Diseño, producción y evaluación de medios para la formación docente. Madrid: Alianza Editorial.

Tallada, A. (2009). La competencia digital y las TAC. Revista BITS, (12). Recuperado de: http://ir.uv.es/15j3ciF

Vivancos, J. (2010). De les TIC a les TAC: reflexions sobre les tecnologies en l'educació. Perspectiva escolar, (344),

2-9.

| Cita recomendada de este artículo

Mato-Vázquez, Dorinda; Castro-Rodríguez, M Montserrat y Pereiro-González, Ma Camino. (2018). "Análisis de materiales didácticos digitales para guiar y/o apoyar el proceso de enseñanza-aprendizaje de las matemáticas". @tic revista d'innovació educativa, 20, 72-79. 